\title{
Evolution of the bulk optical properties of bovine muscles during wet aging
}

\author{
Robbe Van Beers ${ }^{a,{ }^{*}}$, Mito Kokawa ${ }^{a, b}$, Ben Aernouts ${ }^{a, c}$, Rodrigo Watté ${ }^{a}$, Stefaan De \\ Smet ${ }^{d}$, Wouter Saeys ${ }^{a}$ \\ ${ }^{a}$ KU Leuven, Department of Biosystems, MeBioS, Kasteelpark Arenberg 30, 3001 Leuven, \\ Belgium \\ ${ }^{b}$ Analytical Science Division, National Food Research Institute, National Agriculture and \\ Food Research Organization, 2-1-12 Kan-nondai, Tsukuba, Ibaraki 305-8642, Japan \\ ${ }^{c}$ KU Leuven, Department of Microbial and Molecular Systems, Cluster for Bioengineering \\ Technology, Campus Geel, Kleinhoefstraat 4, 2440 Geel, Belgium \\ ${ }^{d}$ Ghent University, Department of Animal Production, Laboratory for Animal Nutrition and \\ Animal Product Quality (LANUPRO), B-9090 Melle, Belgium \\ *Email: wouter.saeys@kuleuven.be \\ Tel: +32 (0) 16377132 \\ Fax: +32(0) 16321994
}

\section{Abstract}

The bulk optical properties (BOP) of two bovine muscles were studied in the $500 \mathrm{~nm}$ to 1850 $\mathrm{nm}$ wavelength range. Over a two-week period of wet aging, the BOP of the biceps femoris (BF) and longissimus lumborum (LL) were determined and related to moisture content, tenderness and cooking loss. The absorption by myoglobin and reduced scattering coefficient were higher in the BF compared to the LL. The scattering anisotropy factor was relatively high ( $>0.95$ for $\mathrm{LL}$ ), representing dominant forward scattering. Two-toning effects in the BF could be attributed to significant scattering differences, as no differences in absorption properties were observed. During wet aging, the anisotropy factor decreased, while tenderness increased. It was hypothesized that this might be related to proteolysis of cytoskeletal proteins. The results show the potential use of BOP to monitor tenderization and the cause of color differences in beef muscles. Moreover, this information could be used to develop and optimize optical sensors for non-destructive meat quality monitoring.

Keywords: Meat quality, Scattering, Absorption, Anisotropy factor, Double integrating spheres, Unscattered transmittance 


\section{Introduction}

34 The meat industry aims for reliable meat quality monitoring throughout the production process in order to guarantee a high quality of the final product (Damez \& Clerjon, 2008; Troy \& Kerry, 2010). Nevertheless, large variability in the muscle type and quality often results in a highly variable end product (Damez \& Clerjon, 2013). For this reason, the meat sector is interested in technology for accurate, fast and non-destructive determination of quality attributes. Both chemical ( $\mathrm{pH}$, color and fat content) and physical parameters (tenderness and juiciness) contribute to the meat appearance and eating experience and, therefore, to the final consumer acceptability.

Optical sensors provide a fast way to non-destructively measure food products. Optical techniques such as vis/NIR spectroscopy (Prieto et al., 2009; Ripoll et al., 2008), spatially and time resolved spectroscopy (Swartling et al., 2003; Xia et al., 2007) and hyperspectral imaging (Elmasry et al., 2012) have been studied to measure quality attributes of many food products, including meat (Nicolaï et al., 2014; Prieto et al., 2009). These methods measure the light which interacted with the sample of interest and which is reflected in the direction of the sensor. The obtained reflectance signals are affected by both the chemical and physical properties of the sample, which are responsible for respectively the absorption and scattering of the propagating light photons (MacDougall, 1982; Nicolaï et al., 2007; Swatland, 1991).

Light scattering in biological tissue is typically caused by local non-uniformities in the physical microstructure. The intensity and the direction of the light scattering depend on the size, the shape and the refractive index-mismatch of the scattering particles (Nicolaï et al., 2007; Peng \& Dhakal, 2015). These non-uniformities can be cell organelles, fibrous structures, air pores,.... The light deflections determine the path length of the photons traveling through the sample (López-Maestresalas et al., 2015). As the chance for a photon to be absorbed in a medium with a given concentration of a certain chromophore is proportional to the photon's 
path length travelled in this medium (cf. Beer-Lambert law), the effects of absorption and scattering are indissolubly connected in the obtained optical measurements (Van Beers et al., 2015). Accordingly, changes in the scattering properties of the sample, altering the photon path length, might be misread as a change in the absorption, related to the composition.

The propagation of light in turbid media, like biological materials, can be described by the radiative transport theory (RTT) which considers the tissue's bulk optical properties (BOP). These BOP include the bulk absorption coefficient $\mu_{a}$, the bulk scattering coefficient $\mu_{s}$ and the angular scattering pattern, represented by the normalized scattering phase function $p(\theta)$ (Tuchin, 2007). This phase function describes the normalized scattering probability as a function of the scattering angle $\theta$, but is often too complex to interpret. Therefore, the mean cosine of the scattering angle, called the anisotropy factor $g$, is generally used instead. This wavelength dependent parameter describes the scattering direction with values ranging from isotropic Rayleigh scattering $(g=0)$ to complete forward scattering $(g=1)$. In most biological tissues, an anisotropy factor close to 1 is found, indicating high forward scattering (Aernouts et al., 2015; Tuchin, 2007). As it is not always possible to estimate the scattering anisotropy, the bulk scattering coefficient and the anisotropy factor are often combined in a lumped parameter, known as the reduced scattering coefficient $\mu_{s}^{\prime}$ (Tuchin, 2007).

For determining the BOP of biological tissues, double integrating spheres (DIS) systems are considered to be the 'golden standard' (Aernouts et al., 2013; Bashkatov, 2005; LópezMaestresalas et al., 2015; Saeys, 2008; Tuchin, 2007; Zamora-Rojas et al., 2013). By measuring a thin sample slab in vitro in-between two integrating spheres, the total reflectance and transmittance can be determined. These measures can then be used to obtain an accurate estimate for $\mu_{a}$ and $\mu_{s}^{\prime}$ through inversion of light propagation models based on radiative transfer theory. By also measuring the unscattered transmittance (UT) of the sample, the bulk extinction coefficient $\mu_{t}$ can be retrieved. Accordingly, the bulk scattering 
coefficient $\mu_{s}$ and the anisotropy factor $g$ can be calculated from $\mu_{a}, \mu_{s}^{\prime}$ and $\mu_{t}$ (Aernouts et al., 2013; López-Maestresalas et al., 2015; Prahl, 2011).

In the past, the BOP of many agro-food products have been characterized using integrating sphere systems to study their relation with the chemical and physical quality attributes of these products. For example, the BOP of onions (Wang \& Li, 2013), apples (Rowe et al., 2014; Saeys et al., 2008; Van Beers, Aernouts, Watté, et al., 2017), milk (Aernouts et al., 2015), potatoes (López-Maestresalas et al., 2015) and pig adipose tissue (Zamora-Rojas et al., 2013) have been measured. The results of these studies have been used as input parameters for simulation purposes, in order to develop novel optical sensors for online or inline quality monitoring (Watté et al., 2016; Zamora-Rojas et al., 2014). However, few reports were found on the measurement of the BOP of bovine muscle tissue. Xia et al. (2007, 2008) used a spatially resolved spectroscopy setup in combination with a fitting procedure based on the diffusion equation to obtain the absorption and reduced scattering coefficient spectra of different beef samples. Zjp \& ten Bosch (1998) estimated the anisotropy factor and bulk scattering coefficient spectrum for a single bovine muscle. However, both studies only covered a wavelength region between $380 \mathrm{~nm}$ and $950 \mathrm{~nm}$, while many important chemical components (fatty acids, proteins, water, etc.) have their major NIR absorption at wavelengths above $1000 \mathrm{~nm}$. Flock et al. (1987) measured the total attenuation coefficient and scattering phase function at a wavelength of $633 \mathrm{~nm}$. To the best of our knowledge, there are no studies reporting the BOP of bovine meat samples for wavelengths above 1000 $\mathrm{nm}$. Moreover, the used DIS setup in this study provides accurate estimates of the BOP values over a large part of the vis/NIR range of the spectrum, even for strongly scattering and absorbing samples (Aernouts et al., 2013). Besides estimating the bulk absorption coefficient and the reduced scattering coefficient, also the anisotropy factor and bulk scattering coefficient can be accurately determined. 
111 Therefore, the main goal of this study was to provide accurate estimations of $\mu_{a}, \mu_{s}, \mu_{s}^{\prime}$ and $g$ 112 for two bovine muscles from $500 \mathrm{~nm}$ to $1850 \mathrm{~nm}$ and the way in which these properties 113 change during wet aging. A DIS setup in combination with a measurement of the unscattered 114 transmittance was used to obtain accurate estimates for the BOP.

\section{Materials and methods}

\section{7}

118

119

120

121

122

123

124

125

126

127

128

129

130

131

132

\subsection{Muscle samples}

Two bovine muscles, longissimus lumborum (LL) and biceps femoris (BF), were collected at a commercial meat handling facility in Belgium (Hemelaer-NV, Opwijk, Belgium). Both muscles were sampled the day after slaughter and originated from one Belgian Blue bull with an age of 19.5 months and a carcass weight at slaughter of $503 \mathrm{~kg}$. Of each muscle, a total of six samples (size $20 \mathrm{~cm} \times 10 \mathrm{~cm} \times 2.5 \mathrm{~cm}$ ) were collected and immediately vacuum packed. For the BF muscle, a high intramuscular variability was expected due to the existence of two-toning, induced by heat shortening (Pastsart et al., 2011; Pastsart et al., 2013). Therefore, one sample of the outer BF (OBF) and one sample of the inner BF (IBF) were used per week for the wet aging experiment. Hence, in the current study, a total of six LL samples, three OBF samples and three IBF samples were considered. All the samples were stored in a refrigerator $\left(4^{\circ} \mathrm{C}\right)$ during the wet aging process. After one day, one week and two weeks of wet aging, each time two LL samples, one IBF and one OBF sample were unpacked. After unpacking, subsamples were taken to perform optical measurements (section 2.2) and reference quality measurements (section 2.3).

\subsection{Meat bulk optical properties}

2.2.1 Double integrating spheres (DIS) and unscattered transmittance (UT) setup 
135 To determine the BOP of the muscle tissue samples, a double integrating spheres (DIS) 136 setup in combination with a measurement of the unscattered transmittance (UT), described 137 by Aernouts et al. (2013), was used. Samples were placed in a sample holder which was 138 located between two Infragold ${ }^{\circledR}$ coated integrating spheres (RT-060-IG, Labsphere Inc., 139 North Sutton, USA). The light collected by the detectors on the sphere in front of the sample

140 and by the sphere on the backside of the sample is a measure for respectively the total 141 reflectance $\left(M_{R}\right)$ and the total transmittance $\left(M_{T}\right)$. In a separate measuring path, the 142 unscattered transmittance $\left(M_{u}\right)$ of the sample was determined. For this, the sample was 143 placed in a sample holder with the detectors positioned at a large distance $(1.5 \mathrm{~m})$ behind the 144 sample. In this way, the contribution of scattered photons to the measurement was limited. A supercontinuum laser (SC450-4, Fianium Ltd., Southampton, UK) in combination with a monochromator (Oriel Cornerstone 260 1/4 m, Newport, Irvine, USA) was used as a tunable

147 monochrome illumination source. The wavelength of the illumination beam was varied from $148500 \mathrm{~nm}$ to $1850 \mathrm{~nm}$ in steps of $5 \mathrm{~nm}$. To measure the different spectra $\left(M_{R}, M_{T}\right.$ and $\left.M_{U}\right)$, a Si 149 detector (PDA100A, Thorlabs Inc., Newton, NJ, USA) and a one-stage Peltier-cooled extended-InGaAS detector (PDA10DT-EC, Thorlabs Inc., Newton, NJ, USA) were used for wavelengths below and above $1050 \mathrm{~nm}$, respectively.

152

All the detectors in the setup were read by a data acquisition card (NI PCI-6251, National Instruments Corporation, TX, USA), while the measurement procedure was programmed in LabView 8.5 (National Instruments Corporation, Austin, TX, USA). More details about the DIS and UT measurement setup can be found in Aernouts et al. (2013).

\subsubsection{Sample preparation and measurements}

Before the meat samples could be measured with the DIS/UT setup, an extensive sample preparation was required. A thin sample slab was needed to ensure sufficient total and unscattered transmission signals. Therefore, two small subsamples of about $3.5 \mathrm{~cm} \times 3.5 \mathrm{~cm}$ $x 1 \mathrm{~cm}$ were cut from the original unpacked sample. These subsamples were embedded in 
an optimal cutting temperature compound (OCT Compound 361603E, WWR International, Radnor, PA, USA) without incorporating air bubbles, as these might cause cracks during freezing. Next, the subsamples were indirectly frozen by putting them in a metal cup submerged in liquid nitrogen. This indirect contact with the liquid nitrogen ensured that the subsample froze without forming cracks. Subsequently, the subsamples were stored at $-80^{\circ} \mathrm{C}$ until the end of the wet aging period (Mager et al., 2007). After all the subsamples had been collected and frozen, they were cut into slices of $0.5 \mathrm{~mm}$ using a microtome-cryostat (Microm HM 560 Cryostat, Thermo Fisher Scientific, Waltham, MA, USA). The slicing was performed perpendicular to the muscle fiber orientation. For the IBF and OBF sample, two slices per subsample were obtained, while for the LL muscle samples, only one slice per subsample was retained. The obtained slices were cut into round disks of $30 \mathrm{~mm}$ diameter and placed in a custom-made glass cuvette. This cuvette consisted of two parallel $1.1 \mathrm{~mm}$ thick glass plates (Borofloat33, Schott, Germany) separated by a $0.55 \mathrm{~mm}$ spacer, as described by Aernouts et al. (2013). The spacer had a circular hole with a diameter of $30 \mathrm{~mm}$, in which the sample fitted. Before and after positioning the sample slab in the cuvette, demineralized water was added to remove unwanted air bubbles and to reduce refractive index mismatches at the boundaries between the glass plates and the sample (Van Beers, Aernouts, Watté, et al., 2017). The cuvette thickness was measured in triplicate for each sample individually. Finally, the cuvette filled with the sample slab was sequentially placed in the sample holder of the DIS and the UT path to acquire the total reflectance $\left(M_{R}\right)$, the total transmittance $\left(M_{T}\right)$ and the unscattered transmittance $\left(M_{u}\right)$ spectra.

\subsubsection{Calculating the bulk optical properties}

After performing the DIS $\left(M_{R}, M_{T}\right)$ and UT $\left(M_{U}\right)$ measurements on the different meat samples, the BOP were estimated using the inverse adding doubling (IAD) routine developed and optimized by Prahl et al. (1993). Next to the $M_{R}, M_{T}$ and $M_{U}$ measurements, also the refractive index of the meat samples was required as an input parameter for the IAD routine.

187 As water represents up to $75 \%$ of the total fresh matter in meat, the sample refractive index 
was expected to be close to the refractive index of water (Prieto et al., 2009). Accordingly, the wavelength-dependent real refractive index of water was adopted from Hale \& Querry 190 (1973) and a wavelength-independent constant was added. Dirckx et al. (2005) found a bovine muscle refractive index of $1.382 \pm 0.004$ at $592 \mathrm{~nm}$, while the refractive index of water

192 at this wavelength is 1.333 (Hale \& Querry, 1973). Based on these findings, a constant of 1930.049 was added to the refractive index of water for all wavelengths. Besides the sample's 194 refractive index, several setup- and sample-related input parameters were required. For 195 these parameters, like the reflectance efficiency of the sphere wall and the diameter of the 196 illumination beam, the values reported by Aernouts et al. (2013) were used.

To avoid unwanted air bubbles and to reduce refractive index mismatches at the boundaries between the glass plates and the sample, water was added to the sample. The effect of the added water on the obtained measurements was corrected for in the estimation of the BOP. To this end, a perfect two-layered water-sample system was assumed. The procedure to correct for the effect of the water layer is described in detail by Van Beers et al. (2017). It involves calculation of the thickness of the water layer by subtracting the thickness of both 203 glass-walls of the cuvette and the thickness of the sample from the total thickness of the 204 cuvette.

All data processing steps, among which the estimation of the BOP through the IAD routine, were performed in Matlab (version 7.10, The Mathworks Inc., Natick, MA, USA). To test whether the mean BOP values differed significantly between the different muscle types, an analysis of variance (1-way ANOVA) per wavelength in combination with a Tukey multiple 210 comparison test was performed in Matlab. For all tests, a significance level of $5 \%$ was used $211 \quad(p-v a l u e=0.05)$. 


\subsection{Meat quality measurements}

214 Destructive reference measurements were performed to determine relevant quality 215 parameters and to monitor them during the wet aging period. First, the total moisture content 216 of the samples was determined in triplicate according to the AOAC Method 950.46 (Leffler et 217 al., 2008). To do so, 8-10 g of raw minced sample (corresponding to about $2 \mathrm{~g}$ of dry 218 material) was dried for 16 to 18 hours at $102^{\circ} \mathrm{C}$ in a hot air oven. Before and after drying, the 219 sample was weighted (Adventurer Pro AV412, OHAUS Corporation, Parsippany, NJ, USA) in 220 order to determine the total moisture content.

221 Tenderness was evaluated according to the Warner-Bratzler shear force (WBSF) method 222 described by Boccard et al. (1981). After collecting sub-samples (for DIS/UT measurements 223 and moisture content determination) from each meat sample, the remaining part was 224 weighed and placed in a thin-walled polyethylene bag. The bag was placed in a water bath 225 (Grant GR150, Grant Instruments Ltd, Shepreth, Cambridgeshire, UK) at $75^{\circ} \mathrm{C}$ for 50 226 minutes, to make sure that the meat center reaches this temperature (Boccard et al., 1981). Next, the packed sample was cooled for 40 minutes using running tap water. After cooling, the sample was unpacked and weighed again to determine the cooking loss, after which it was placed in a refrigerator at $4^{\circ} \mathrm{C}$ overnight. As only one sample of both the OBF and IBF were used every aging time, no replicates were possible. For the LL muscle, two samples per aging time were measured. For each meat sample, 10 cylindrical cores (diameter of 1.25 $\mathrm{cm}$ ) parallel to the muscle fiber direction were taken to use in the Warner-Bratzler shear force (WBSF) measurement. The maximum force which is needed to press a V-shaped cutting blade $\left(60^{\circ} \mathrm{V}\right.$-notch) through the meat cylinder was measured with a universal testing machine (Type LS1 Material Tester, LLoyd materials testing, West Sussex, UK). This measurement was repeated for 10 cylinders per meat sample, and the mean maximum force

237 value is considered the WBSF value. Higher WBSF values correspond to lower meat 238 tenderness (Gruber et al., 2006). 
To test whether the mean values of the measured quality traits (total moisture content,

240 cooking loss and tenderness) differed significantly between the muscle types and between

241 days postmortem (2, 9 and 16 days pm), an analysis of variance (2-way ANOVA) in 242 combination with a Tukey multiple comparison test was performed in Matlab.

\section{3. Results and Discussion}

245

246

247

248

249

\subsection{Meat quality measurements}

In Table 1 the results of the meat quality measurements are shown according to muscle type and aging time.

Table 1 Mean values \pm standard deviation for water content (\%), cooking loss (\%) and Warner-Bratzler shear force (N) during wet aging for the biceps femoris (BF) and longissimus lumborum (LL) muscles.

Time postmortem (days)

\begin{tabular}{lcccc}
\hline & Muscle & $\mathbf{2}$ & $\mathbf{9}$ & $\mathbf{1 6}$ \\
\hline WBSF (N) & BF & $31.81 \pm 10.00^{\text {a }}$ & $31.63 \pm 9.04^{\text {a }}$ & $26.06 \pm 8.69^{\text {a }}$ \\
& OBF & $40.20 \pm 13.81^{\text {ab }}$ & $33.57 \pm 7.45^{\text {a }}$ & $30.63 \pm 9.93^{\text {a }}$ \\
& LL & $78.46 \pm 19.23^{\circ}$ & $56.92 \pm 24.90^{\text {b }}$ & $30.61 \pm 8.54^{\text {a }}$ \\
\hline Moisture content (\%) & IBF & $73.05 \pm 0.27^{\text {ab }}$ & $72.52 \pm 0.21^{\text {a }}$ & $73.06 \pm 0.12^{\text {ab }}$ \\
& OBF & $72.64 \pm 0.13^{\text {a }}$ & $73.13 \pm 0.07^{\text {ac }}$ & $73.09 \pm 0.10^{\text {ac }}$ \\
\hline Cooking loss (\%) & LL & $74.39 \pm 0.41^{\text {a }}$ & $73.69 \pm 0.35^{\text {bc }}$ & $73.79 \pm 0.22^{\text {cd }}$ \\
& IBF & 22.85 & 23.92 & 26.80 \\
& OBF & 25.70 & 24.08 & 25.85 \\
& LL & $18.22 \pm 0.88^{a}$ & $27.50 \pm 11.10^{a}$ & $25.35 \pm 0.45^{a}$
\end{tabular}
a common letter superscript are significantly different at $P<0.05$.

As can be noticed from Table 1, a significant decrease in WBSF values appeared during wet aging of the LL muscle. This observation is consistent with the results reported by other 
decrease in WBSF was also expected in the BF muscle (Gruber et al., 2006). However, 257 although a decrease in the WBSF values of the BF muscle samples in function of the time postmortem can be noticed (Table 1), this effect was not significant. The moisture content of 259 the LL muscle decreased in the period between day 2 and 9 postmortem, after which it slightly increased again. For the BF muscle, on the other hand, no significant differences 261 were noted between the different types (IBF vs. OBF) and days postmortem (Table 1). In 262 contrast to these results, Li et al. (2008) found an increase in moisture content of the 263 semitendinosus muscle from day 4 to day 14 of wet aging, after which a small decrease was 264 noticed until day 28. In addition, Li et al. (2008) also suggested that wet aging resulted in an 265 increase of cooking losses. Nevertheless, other researchers found no clear changes in 266 cooking losses over a five week wet aging period (Jeremiah \& Gibson, 2003). In this study, as only a limited number of samples was measured, no significant differences in cooking loss

268 could be identified. Nevertheless, both in the IBF and LL muscle samples, an increasing 269 trend can be noticed from Table 1.

\subsection{Bulk optical properties of bovine muscles}

271 In Figure 1 the mean value and standard deviation (error bars) for the estimated bulk 272 absorption coefficient (Figure 1a) and reduced scattering coefficient (Figure 1b) are shown 273 for both the $\mathrm{LL}$ and $\mathrm{BF}$ muscle samples. The separation between the IBF and OBF is shown 274 as well. The mean values and standard deviations were calculated over the total duration of 275 the study (day 2 until day 16 postmortem). For each muscle type considered, this involved 12 276 sample slices 
a)

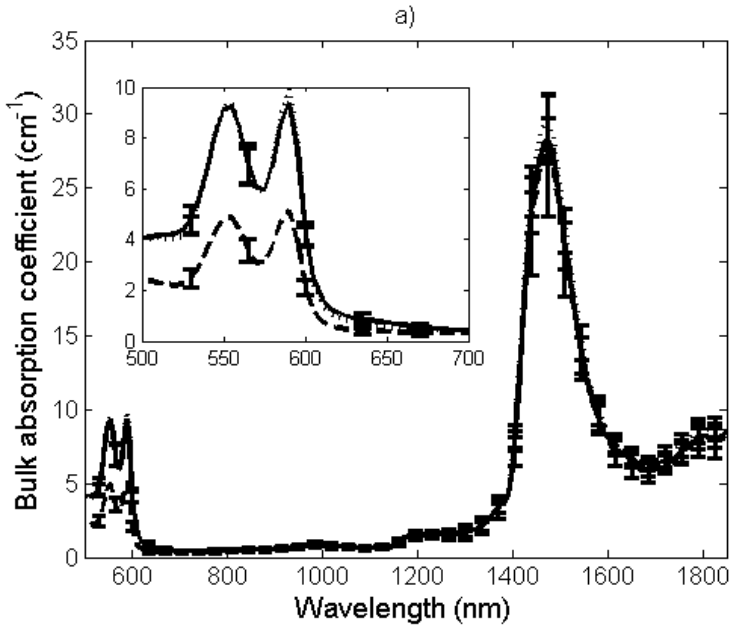

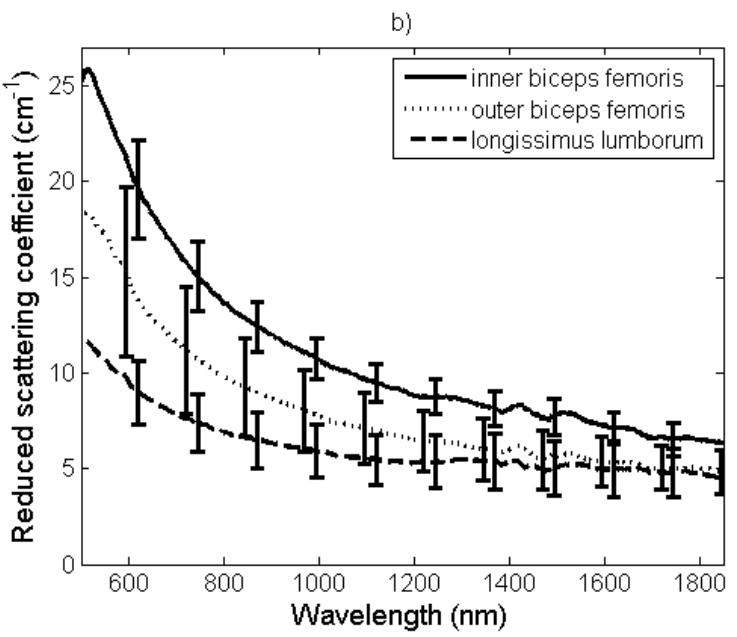

277

Figure 1 (a) Mean bulk absorption coefficient $\mu_{a}$ and (b) mean reduced scattering coefficient $\mu_{s}^{\prime}$ of the measured bovine muscles over a two-week wet aging period. The inset figure on the left shows the mean absorption coefficient over a smaller wavelength range from $500 \mathrm{~nm}$ to $700 \mathrm{~nm}$. The error bars indicate the standard deviation.

\subsubsection{Water and myoglobin dominate the absorption coefficient spectra of muscle tissue}

In Figure 1a, some clear absorption features can be observed. Water is one of the main constituents present in muscle tissue and makes up about $75 \%$ of the total fresh matter (Prieto et al., 2009) (Table 1). Accordingly, some distinctive absorption peaks can be observed at $970 \mathrm{~nm}, 1200 \mathrm{~nm}$ and $1450 \mathrm{~nm}$, which can be attributed to absorption by the O$\mathrm{H}$ bonds in water. While water is mainly absorbing in the NIR range $(700-1850 \mathrm{~nm})$, myoglobin is a meat component which absorbs most of the visible light $(400-700 \mathrm{~nm})$. Myoglobin is an oxygen-binding molecule, which can be present in three different forms: oxymyoglobin, deoxymyoglobin and metmyoglobin (Prieto et al., 2009). Prior to the DIS and UT measurements, the $0.5 \mathrm{~mm}$ thick samples were prepared in an aerobic environment. Accordingly, the myoglobin was mainly present in the oxygenated state: oxymyoglobin. The latter has a distinctive dual absorption peak at $544 \mathrm{~nm}$ and $582 \mathrm{~nm}$ (Cozzolino \& Murray, 2004; Millar et al., 1996). These absorption peaks, resulting in a bright red color, are clearly visible in Figure 1a. Apart from these dominant absorbers, also protein and intramuscular fat affect the NIR spectrum due to the absorption by $\mathrm{N}-\mathrm{H}$ bonds $(1460-1570 \mathrm{~nm})$ and $\mathrm{C}-\mathrm{H}$ bonds (1100-1400 nm and $1700 \mathrm{~nm}$ ), respectively (Prieto et al., 2009). The vis/NIR absorption coefficient spectra of BF and LL muscles were most different at the absorption region of 
300 myoglobin (Figure 1a inset). This variation is most likely related to a different myoglobin 301 concentration in these two muscle types (Rickansrud \& Henrickson, 1967; Von Seggern et 302 al., 2005). Moreover, Rickansrud \& Henrickson (1967) found a higher total pigment 303 concentration of $4.85 \mathrm{mg} / \mathrm{g}$ in the BF muscle compared to $3.97 \mathrm{mg} / \mathrm{g}$ for the LL muscle. 304 There was, however, no significant difference in the absorption between the inner and outer 305 BF muscle samples.

307 3.2.2 Higher scattering explains the lighter color of the inner biceps femoris muscle

308 The scattering behavior in the muscles is illustrated in Figure 1b, showing the mean reduced 309 scattering coefficient calculated over the total duration of the study (day 2 until day 16 310 postmortem). From this figure, a clear decreasing trend can be observed with increasing 311 wavelength, which is typical for biological tissues (Bashkatov et al., 2005; Jacques, 2013). At 312 all wavelengths, a significantly higher $\mu_{s}^{\prime}$ was found for the IBF samples compared to the $313 \mathrm{OBF}$ and the LL samples, while the $\mu_{s}^{\prime}$ of the OBF sample was only significantly higher than 314 the LL muscle for wavelengths below $1175 \mathrm{~nm}$.

316 In Figure 2, the measured $\mu_{s}^{\prime}$ spectra of the LL muscle are compared to the values obtained 317 by Xia et al. (2008) over a much smaller wavelength range (600 $\mathrm{nm}$ to $950 \mathrm{~nm}$ ). 


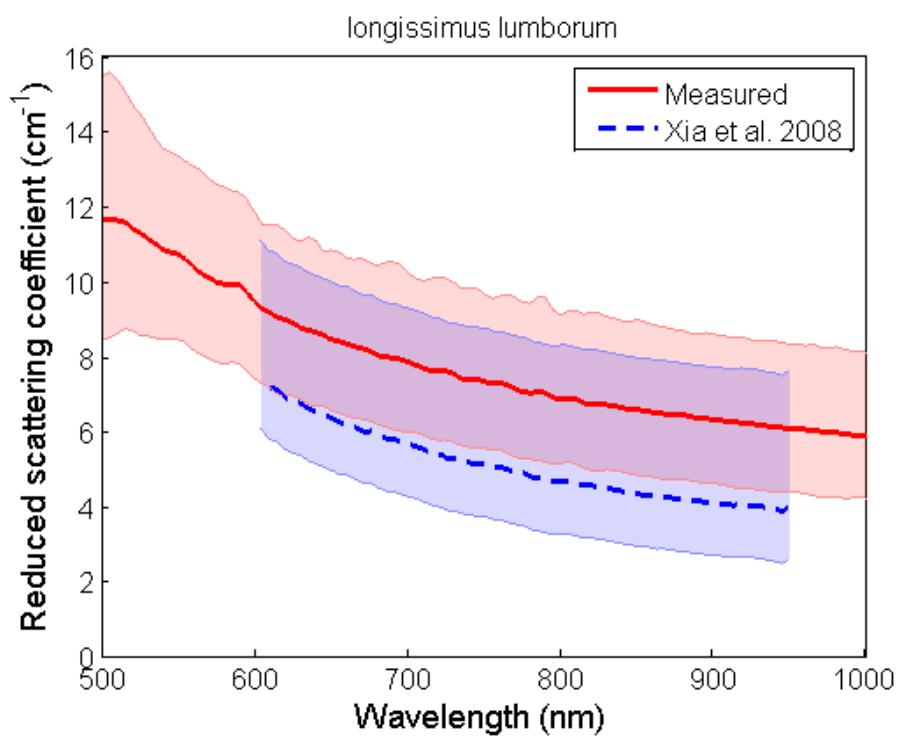

Figure 2 Comparison of the reduced scattering coefficient in the 500 to $1000 \mathrm{~nm}$ range measured for the longissimus lumborum sample to the values reported by Xia et al. (2008). The lines indicate the mean values both in this study and by Xia et al. (2008), while the areas indicate the ranges.

Xia et al. (2008) measured four different muscles, including the longissimus dorsi, which is a former designation to describe the longissimus lumborum (Kauffman, 1990). In Figure 2, a similar magnitude and overall trend of the $\mu_{s}^{\prime}$ values over the measured wavelength range can be observed although the mean values they reported were somewhat lower. Moreover, the BOP values obtained in this research illustrate the intramuscular variation in a single LL muscle, as multiple samples from the same LL muscle, originating from one bull, were measured. In the $\mu_{s}^{\prime}$ values reported by Xia et al. (2008), the intermuscular variation was captured, as 92 muscles were considered. In their study, the $\mathrm{LL} \mu_{s}^{\prime}$ values ranged from $4 \mathrm{~cm}^{-}$ ${ }^{1}$ to $9 \mathrm{~cm}^{-1}$ at $721 \mathrm{~nm}$, which is in line with the results obtained in this study. The range of obtained $\mu_{s}^{\prime}$ values is shown as the blue band in Figure 2. It should be noted that the results in this study were obtained from DIS and UT measurements in combination with an IAD routine, while the results in the work by Xia et al. (2008) were derived from measuring the diffuse reflectance at several distances from the point of illumination. The used DIS/UT setup in this study provides a reliable separation between the bulk optical properties, even for strongly scattering and absorbing biological samples (Aernouts et al., 2013; López- 
estimations of $\mu_{a}, \mu_{s}^{\prime}$ and the anisotropy factor $g$ are obtained. In addition, Xia et al. (2008) dry aged the $L L$ muscle samples at $4^{\circ} \mathrm{C}$ for $1,7,14$ or 21 days.

342 In Figure 3a, the bulk scattering coefficient $\mu_{s}$ spectra are shown for the different muscle samples averaged over the entire wet aging period, while Figure $3 b$ shows the anisotropy 344 factor $g$. For each muscle type considered, this involved 12 sample slices collected over the entire wet aging period.
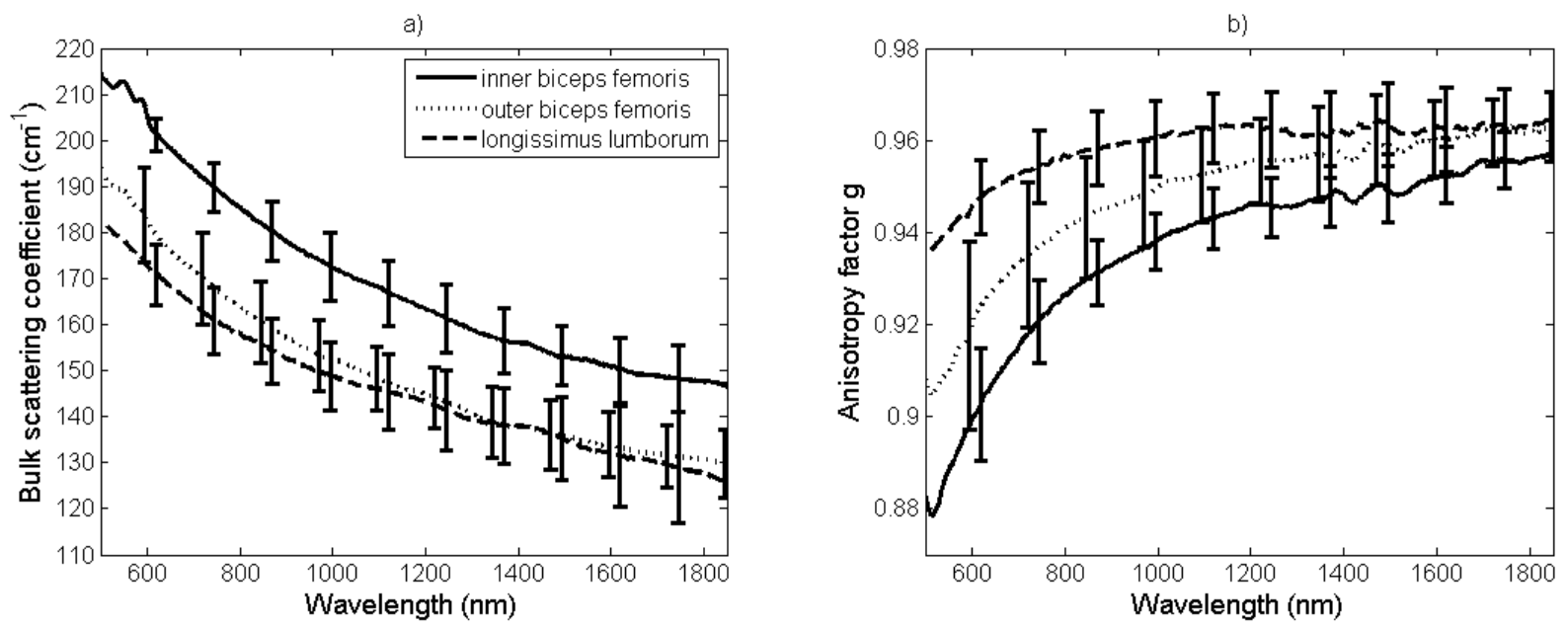

Figure 3 (a) Mean bulk scattering coefficient $\mu_{s}$ and (b) mean anisotropy factor $g$ of two bovine muscles

In Figure 3a, a significant difference in the bulk scattering coefficient of the IBF compared to the other muscle samples can be observed for all wavelengths. Additionally, it was found that the bulk scattering coefficient spectra of the OBF were significantly different from those of the LL muscle for wavelengths below $700 \mathrm{~nm}$. The IBF muscle samples had an overall higher $\mu_{s}$ with mean values up to $185 \mathrm{~cm}^{-1}$ at $800 \mathrm{~nm}$, while at the same wavelength, the $\mathrm{OBF}$ and the LL samples had a mean value of $164 \mathrm{~cm}^{-1}$ and $158 \mathrm{~cm}^{-1}$, respectively. For the anisotropy factor $g$, on the other hand, also significant differences between the IBF and LL samples were found over the entire wavelength range. The OBF only showed significant differences with the LL samples below $1195 \mathrm{~nm}$, and with the IBF samples below $1370 \mathrm{~nm}$. For all 
scattering, with a mean $g$-value at $800 \mathrm{~nm}$ of $0.927,0.941$ and 0.957 for the IBF, OBF and LL samples, respectively. Moreover, the anisotropy had an increasing trend with increasing wavelengths, typically observed in biological tissues (Jacques, 2013).

According to Xia et al. (2008), two major structural characteristics influence the scattering properties of muscles: the collagen content and protein-protein interactions within the sarcomere. Rhee et al. (2004) showed a significant difference $(p<0.05)$ in the collagen concentration between $\mathrm{BF}$ and $\mathrm{LL}$, with $8.74 \pm 1.12 \mathrm{mg} / \mathrm{g}$ for the BF compared to $4.52 \pm 0.66$ $\mathrm{mg} / \mathrm{g}$ for the LL. Moreover, it was found that the sarcomere length of both muscles is very similar (Rhee et al., 2004). Therefore, a large part of the observed differences in the scattering properties can most likely be attributed to the concentration of collagen.

Moreover, as both muscles originated from a different part of the animal, the muscle fiber composition was most likely different (Kirchofer et al., 2002). Both the BF and the LL are 372 categorized as white muscles, mainly consisting of Type IIX muscle fibers. According to 373 Kirchofer et al. (2002), the BF and LL muscles contain respectively $49.3 \pm 4 \%$ and $43.2 \pm 4.4 \%$ 374 of Type IIX fibers. Besides this type of muscle fiber, also Type I fibers $(21.7 \pm 1.9 \%$ for the BF 375 to $35 \pm 1.4 \%$ for the LL) and Type lla fibers $(29 \pm 2.3 \%$ for the BF to $21.8 \pm 3.4 \%$ for the $L L)$ are present. Overall, the Type II fibers are thicker in comparison with Type I fibers (Kirchofer et al., 2002). Considering the different diameters and the composition, the overall fiber thickness in BF muscles is smaller than in LL muscles.

The observed intramuscular scattering difference between the BF samples is most likely related to the effect of two-toning, which has been observed in the BF muscle of Belgian Blue cattle (Pastsart et al., 2011; Pastsart et al., 2013). The obtained results suggest that this visual two-toning effect is caused by differences in the scattering properties rather than in the absorption properties (Figure 1 and Figure 3). The BF intramuscular differences in the amount of scattering could be related to a difference in the amount of protein denaturation. 
Although not measured in the current study, Pastsart et al. (2013) suggested increased protein denaturation in IBF muscle samples of Belgian Blue cattle due to a faster postmortem $\mathrm{pH}$ decline. A similar post-mortem decline in $\mathrm{pH}$ is seen in pork muscles, causing pale, soft and exudative (PSE) meat. This PSE meat is related to an increased amount of scattering due to the deposition of denatured sarcoplasmic proteins on the myofibrils (MacDougall, 1982; Swatland, 1994, 2004; Van Oeckel et al., 1999). The increased protein denaturation in the IBF samples might have a similar effect, increasing $\mu_{s}$ (Figure 3a). At the same time, this denaturation of sarcoplasmic proteins might decrease the overall particle size, which results in a decrease in the scattering anisotropy $g$ (Figure 3b). According to the Mie scattering theory, a lower anisotropy factor indicates smaller scattering particles (Yavari, 2006).

Zijp \& ten Bosch (1998) also estimated the bulk scattering coefficient and the anisotropy factor of bovine meat samples separately. They measured the psoas major at 9 discrete wavelengths between $550 \mathrm{~nm}$ and $833 \mathrm{~nm}$ and found a mean anisotropy factor around 0.96 and a bulk scattering coefficient of $150 \mathrm{~cm}^{-1}$. The anisotropy factor showed an increase from around 0.95 at $550 \mathrm{~nm}$ towards 0.97 at $833 \mathrm{~nm}$ (Zijp \& ten Bosch, 1998). Flock et al. (1987) measured the scattering phase function and anisotropy factor $g$ of bovine muscle tissue, resulting in a value of $0.954 \pm 0.016$ for $g$ at a wavelength of $632.8 \mathrm{~nm}$. In the current study, a larger wavelength range and different muscles were measured. However, in the wavelength range which they have in common, the obtained results in Figure 3 for the LL muscle are in agreement with the results obtained by both Zijp \& ten Bosch (1998) and Flock et al. (1987).

\subsection{Evolution of bulk optical properties during wet aging}

408 So far, the BOP of the muscles were presented after averaging over the entire wet aging period (2 - 16 days postmortem). In Figure 4, the evolution of the measured BOP during this wet aging period is illustrated for some selected wavelengths. The evolution of $\mu_{a}$ is shown at

$411545 \mathrm{~nm}$, corresponding to one of the absorption wavelengths of oxymyoglobin (Figure 1a). 
were present at this wavelength, while this wavelength represents the scattering behavior of

414 the muscles well. Each week measurements were performed on four sample slices per 415 muscle sample, shown as a mean value and standard deviation.
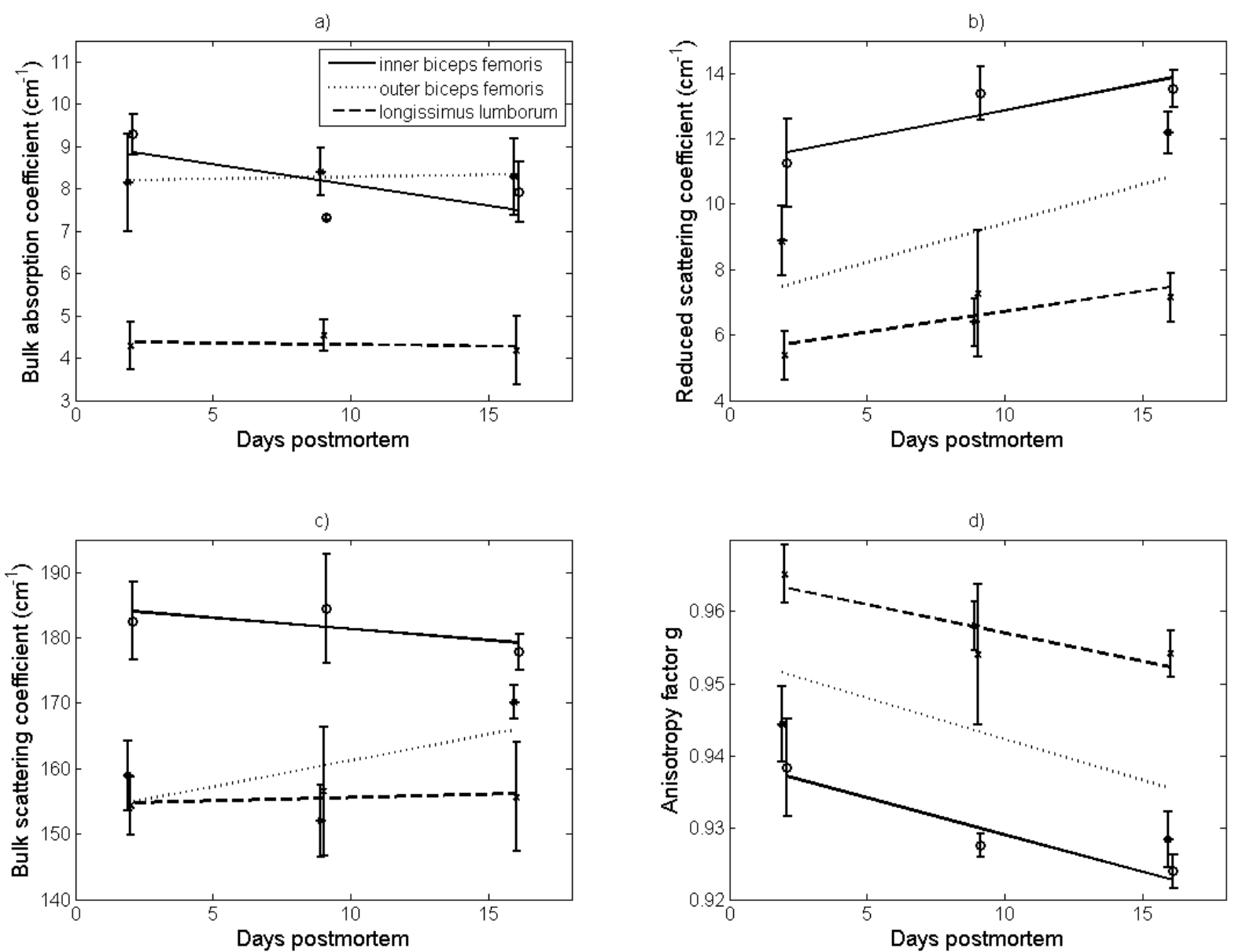

Figure 4 Evolution of the bulk optical properties of two bovine muscles during a two-week wet aging period. (a) The bulk absorption coefficient $\mu_{a}$, (b) the reduced scattering coefficient $\mu_{s}^{\prime}$, (c) the bulk scattering coefficient $\mu_{s}$ and (d) the anisotropy factor $g$. The absorption coefficient is shown at a wavelength of $545 \mathrm{~nm}$, while the other optical properties are shown at a wavelength of $850 \mathrm{~nm}$. The error bars indicate the standard deviation.

422

The decreasing trend of the absorption coefficient at $545 \mathrm{~nm}$ (Figure 4a), representing the absorption by myoglobin, was found to be significant in the IBF muscle samples only. This might be related to the higher protein denaturation found in the IBF, as suggested by Pastsart et al. (2013). Additionally, it was found that the bulk scattering coefficient did not change significantly during wet aging (Figure 4c). Nevertheless, clear increasing and decreasing trends were observed over time for respectively the reduced scattering coefficient 
429 (Figure 4b) and the anisotropy factor (Figure 4d). For the LL and OBF muscle samples, the 430 increasing trend of the reduced scattering coefficient was found to be non-significant. 431 However, the p-values for these trends were close to 0.05 . For the anisotropy factor, only the 432 decreasing trend of the OBF sample was non-significant. Since the bulk scattering coefficient 433 did not change significantly over time, the evolution of the anisotropy factors and the reduced 434 scattering coefficients were negatively correlated.

435 The significant decreases in the anisotropy factor during the wet aging period could be related to a change in the size and/or shape of the scattering particles. During wet aging, the proteolysis of cytoskeletal proteins is considered the main cause for increasing tenderness 438 (Koohmaraie, 1994; Xia et al., 2008). This process causes the fragmentation of myofibrillar structures in the muscle tissue, which likely affects the overall size of the scattering particles. Xia et al. (2008) determined the reduced scattering coefficient of four beef muscles during a 21-day period of dry aging. Their results showed that WBSF was significantly changing the first 7 days of aging, while $\mu_{s}^{\prime}$ increased during the same period. Our results indicate a similar trend in both WBSF (Table 1) and $\mu_{s}^{\prime}$ values (Figure 4b) during wet aging, possibly caused by changes in the overall particle size.

\section{General discussion}

447 One of the requirements to use the IAD algorithm for the calculation of BOP values from 448 integrating sphere measurements, is that the measured samples are homogeneous (Prahl et 449 al., 1993). However, the measured muscle samples will be more heterogeneous, as for 450 example air pores, color differences, blood vessels and connective tissue can be present. 451 Although this effect on the eventual estimation of optical properties is expected to be limited, 452 a more complex modelling strategy like the meshed Monte Carlo method described by Watté 453 et al. (2015) could provide added value in this context. In addition to these possible 454 inconsistencies, muscle tissue is highly anisotropic because of the present muscle fibers, 455 which can affect light propagation (Elliott, 1967; Van Beers, Aernouts, Reis, \& Saeys, 2017). 
Although the effects of this muscle anisotropy on light propagation have been reported to be clearly present in different types of muscle tissue (Kienle, Foschum, \& Hohmann, 2013; Ranasinghesagara \& Yao, 2007), the impact of this anisotropy is expected to be limited due to the measurement of thin samples $(0.5 \mathrm{~mm}$ in thickness). Nevertheless, it is recommended to study the effects of muscle fiber orientation on thin slice measurements in more detail.

The sample preparation was crucial in order to retrieve an accurate and reliable 462 measurement of the unscattered transmittance, which is essential for the correct estimation of both the bulk scattering coefficient and the scattering anisotropy factor (Aernouts et al., 2013; López-Maestresalas et al., 2015). However, this sample preparation involved the cutting of the samples using a cryostat, which proved to be more straightforward for the BF muscle compared to the LL muscle. This might be related to the difference in fiber structure between both muscles (Kirchofer et al., 2002). Moreover, it resulted in a higher number of successful slices for the BF muscle in comparison to the LL muscle. As a result, two slices were obtained for both the OBF and IBF subsamples, while only one slice was retained for the LL subsamples. Overall, this resulted in an equal number of four slices each measurement week for each muscle type, as more LL subsamples per week were 472 considered. However, a higher variation in the results of the LL muscle could be related to the fact that the four slices obtained each week originated from more anatomically different muscle locations in comparison to the OBF and IBF slices. This might explain why some of the observed trends in paragraph 3.3 are not significant. Nevertheless, the general trends in both muscles are similar and in accordance with literature (Xia et al., 2008). In addition, the sample preparation involved a freezing and thawing step. For the freezing of the samples, a 478 rapid freezing using indirect contact with liquid nitrogen was used to minimize the formation 479 of large ice crystals and cracks. However, also the thawing of the samples could have 480 affected the sample (Sen \& Sharma, 2004; X. Xia, Kong, Liu, Diao, \& Liu, 2012). The thawing of the $0.5 \mathrm{~mm}$ thickness slices was performed by adding demineralized water at room temperature. Although small effects of these processing steps might have been present, still 
a good agreement was obtained with the results reported by other researchers for studies not including the freezing and thawing of samples (Figure 2).

The evolution of the BOP was investigated at two distinct wavelengths, one related to the absorption of oxymyoglobin and the other related to light scattering. Other wavelengths might be of interest as these relate to the absorption of water, protein content or intramuscular fat. Nevertheless, as demineralized water was added to the samples before measuring, the NIR part of the spectrum is likely to be influenced. For this reason, no evolutions in the NIR region were included in section 3.3.

Besides the optical measurement, the evolution of meat quality traits was also monitored during the wet aging period. The measurement of the WBSF on 10 cylindrical cores of each muscle resulted in a high standard deviation ranging from 7.45 to $24.9 \mathrm{~N}$ (Table 1). While a significant decrease in the WBSF values was observed for the LL muscle, the decreasing trend was found to be insignificant for the BF muscle samples. This is in contradiction with the findings of Gruber et al. (2006), who reported a significant decrease in the WBSF values for both muscle types. As the measurements in this study were performed on the muscles of only one bull, it is recommended to increase the number of samples and animals in future research. This could confirm the observed trends, both in the reference and optical measurements.

Despite of these shortcomings, the current study provides insights in the BOP of bovine meat samples and their evolution during wet aging. These BOP values provide valuable 504 information for the development and optimization of novel optical sensors for non-destructive 505 quality monitoring in the meat industry. To this end, the obtained BOP values can be used as an input for simulation studies to model the light propagation in order to efficiently evaluate different designs of an optical sensor and novel data processing techniques (Watté et al., 2015a; Watté et al., 2015b). In addition, knowledge on the changes in the interaction of light 
509 with muscle tissue during wet aging allows to evaluate the potential of optical measuring 510 systems to monitor meat quality during wet aging.

\section{Conclusions}

513 The bulk absorption coefficient, reduced scattering coefficient, bulk scattering coefficient and

514 anisotropy factor spectra of the longissimus lumborum (LL) and the biceps femoris (BF) were 515 determined at 2, 8 and 16 days postmortem. The BF muscle was further divided into two 516 subgroups, the outer (OBF) and inner BF (IBF), in order to study the effect of two-toning on 517 the estimated optical properties. The absorption coefficient showed distinct absorption 518 features of myoglobin at $544 \mathrm{~nm}$ and $582 \mathrm{~nm}$, and of water at $970 \mathrm{~nm}, 1200 \mathrm{~nm}$ and 1450

$519 \mathrm{~nm}$. Moreover, it was found that the BF expressed a significantly higher absorption in the 520 visible range of the spectrum, attributed to myoglobin, compared to the LL muscle. However, 521 no significant difference was found between the OBF and IBF samples. Furthermore, the 522 reduced scattering coefficient was significantly higher for the IBF muscle over the entire 523 wavelength range measured. This difference was mainly caused by a significantly lower 524 anisotropy factor for the BF muscle. In addition, the anisotropy factor for both muscles was 525 close to 1, indicating a high forward scattering, with mean values of up to 0.96 at $800 \mathrm{~nm}$ for 526 the LL muscle. Clear differences between the IBF and OBF samples were found for all 527 scattering properties. It was hypothesized that these may have been caused by an increased 528 degree of protein denaturation in the IBF samples, due to a faster post-mortem pH decline. 529 As no difference in absorption was observed between the OBF and IBF samples, the visual 530 effect of two-toning is mainly related to light scattering. During wet aging, a significant 531 decrease in the measured anisotropy factor was noticed in both the LL and IBF samples.

532 During the same period, the LL tenderness increased. Both observations are most likely 533 related to the proteolysis of cytoskeletal proteins during the wet aging period. 
534 This study provides novel insights in the relation between the bulk optical properties and the 535 quality attributes of bovine meat samples during wet aging. This information is essential for 536 understanding light propagation in bovine muscle tissue and to optimize data processing 537 algorithms and innovative optical sensors for meat quality monitoring.

538

\section{Acknowledgements}

540 Robbe Van Beers was funded by the Institute for the Promotion of Innovation through 541 Science and Technology in Flanders (IWT-Flanders, grant number 131777). Mito Kokawa

542 was funded as a postdoctoral fellow of the Japan Society for the Promotion of Science 543 (JSPS). Ben Aernouts was funded as a postdoctoral fellow of the Research Foundation 544 Flanders (FWO, Brussels, Belgium, grant number 12K3916N). Md. Hafizur Rahman Bhuyian

545 is acknowledged for his valuable exploratory work in determining the BOP of beef samples.

546 Lut Noterdaeme and Pieter Vancamp, from the KU Leuven division of animal physiology and

547 neurobiology, are acknowledged for their advice and assistance in preparing the samples

548 slices with the microtome-cryostat. The authors would also like to thank the commercial meat 549 handling facility Hemelaer-NV in Belgium for providing the meat samples. 


\section{References}

551

552

553

554

555

556

557

558

559

560

561

562

563

564

565

566

567

568

569

570

571

572

573

574

575

576

577

578

579

580

581

582

583

584

585

586

587

588

589

590

591

592

593

594

595

596

597

598

599

600

601

602

Aernouts, B., Van Beers, R., Watté, R., Huybrechts, T., Jordens, J., Vermeulen, D., ... Saeys, W. (2015). Effect of ultrasonic homogenization on the Vis/NIR bulk optical properties of milk. Colloids and Surfaces B: Biointerfaces, 126, 510-519. http://doi.org/10.1016/j.colsurfb.2015.01.004

Aernouts, B., Van Beers, R., Watté, R., Huybrechts, T., Lammertyn, J., \& Saeys, W. (2015). Visible and near-infrared bulk optical properties of raw milk. Journal of Dairy Science, 98(7), 6727-6738. http://doi.org/10.3168/jds.2015-9630

Aernouts, B., Zamora-Rojas, E., Van Beers, R., Watté, R., Wang, L., Tsuta, M., ... Saeys, W. (2013). Supercontinuum laser based optical characterization of Intralipid® phantoms in the $500-2250 \mathrm{~nm}$ range. Optics Express, 21(26), 32450-67. http://doi.org/10.1364/OE.21.032450

Bashkatov, A. N., Genina, E. A., Kochubey, V. I., \& Tuchin, V. V. (2005). Optical properties of human skin, subcutaneous and mucous tissues in the wavelength range from 400 to $2000 \mathrm{~nm}$. Journal of Physics D: Applied Physics, 38(15), 2543-2555. http://doi.org/10.1088/0022-3727/38/15/004

Boccard, R., Buchter, L., Casteels, E., Cosentino, E., Dransfield, E., Hood, D. ., ... Touraille, C. (1981). Procedures for measuring meat quality characteristics in beef production experiments. Report of a working group in the commission of the European communities' (CEC) beef production research programme. Livestock Production Science, 8(5), 385-397. http://doi.org/10.1016/0301-6226(81)90061-0

Bratcher, C. L., Johnson, D. D., Littell, R. C., \& Gwartney, B. L. (2005). The effects of quality grade, aging, and location within muscle on Warner-Bratzler shear force in beef muscles of locomotion. Meat Science, 70(2), 279-284. http://doi.org/http://dx.doi.org/10.1016/j.meatsci.2005.01.013

Cozzolino, D., \& Murray, I. (2004). Identification of animal meat muscles by visible and near infrared reflectance spectroscopy. LWT - Food Science and Technology, 37(4), 447452. http://doi.org/10.1016/j.Iwt.2003.10.013

Damez, J.-L., \& Clerjon, S. (2013). Quantifying and predicting meat and meat products quality attributes using electromagnetic waves: An overview. Meat Science, 95(4), 879896. http://doi.org/10.1016/j.meatsci.2013.04.037

Damez, J. L., \& Clerjon, S. (2008). Meat quality assessment using biophysical methods related to meat structure. Meat Science, 80(1), 132-149. http://doi.org/10.1016/j.meatsci.2008.05.039

Dirckx, J., Kuypers, L., \& Decraemer, W. (2005). Refractive index of tissue measured with confocal microscopy. J. Biomed. Opt. http://doi.org/10.1117/1.1993487

Elliott, R. J. (1967). EFFECT OF OPTICAL SYSTEMS AND SAMPLE PREPARATION ON THE VISIBLE REFLECTION SPECTRA OF PORK MUSCLE. J. Sci. Fd Agric., 18(August), 332-338.

Elmasry, G., Sun, D. W., \& Allen, P. (2012). Near-infrared hyperspectral imaging for predicting colour, $\mathrm{pH}$ and tenderness of fresh beef. Journal of Food Engineering, 110(1), 127-140. http://doi.org/10.1016/j.jfoodeng.2011.11.028

Flock, S. T., Wilson, B. C., \& Patterson, M. S. (1987). Total attenuation coefficients and scattering phase functions of tissues and phantom materials at $633 \mathrm{~nm}$. Medical Physics, 14(5), 835-841. http://doi.org/10.1118/1.596010

Gruber, S. L., Tatum, J. D., Scanga, J. A., Chapman, P. L., Smith, G. C., \& Belk, K. E. (2006). Effects of postmortem aging and USDA quality grade on Warner-Bratzler shear force values of seventeen individual beef muscles. Journal of Animal Science, 84(12), 3387-3396. http://doi.org/10.2527/jas.2006-194

Hale, G. M., \& Querry, M. R. (1973). Optical Constants of Water in the 200-nm to 200Wavelength Region. Applied Optics, 12(3), 555-563. http://doi.org/10.1364/AO.12.000555

Jacques, S. L. (2013). Optical Properties of Biological Tissues: A Review. Physics in 
Medicine and Biology, 58(11), R37-61. http://doi.org/10.1088/0031-9155/58/11/R37

Jeremiah, L. E., \& Gibson, L. L. (2003). The effects of postmortem product handling and aging time on beef palatability. Food Research International, 36(9-10), 929-941. http://doi.org/http://dx.doi.org/10.1016/S0963-9969(03)00102-9

Kauffman, R. G., Habel, R. E., Smulders, F. J. M., Hartman, W., \& Bergström, P. L. (1990). Recommended terminology for the muscle commonly designated "Longissimus dorsi." Meat Science, 28, 259-265.

Kienle, A., Foschum, F., \& Hohmann, A. (2013). Light propagation in structural anisotropic media in the steady-state and time domains. Physics in Medicine and Biology, 58, 6205-23. http://doi.org/10.1088/0031-9155/58/17/6205

Kirchofer, K. S., Calkins, C. R., \& Gwartney, B. L. (2002). Fiber-type composition of muscles of the beef chuck and round. Journal of Animal Science, 80, 2872-2878.

Koohmaraie, M. (1994). Muscle proteinases and meat aging. Meat Science, 36(1-2), 93104. http://doi.org/http://dx.doi.org/10.1016/0309-1740(94)90036-1

Leffler, T. P., Moser, C. R., McManus, B. J., Urh, J. J., Keeton, J. T., Claflin, A., ... Steiner, G. (2008). Determination of moisture and fat in meats by microwave and nuclear magnetic resonance analysis: Collaborative study. Journal of AOAC International, 91(4), 802-810.

Li, C., Zhou, G., \& Xu, X. (2008). Changes of meat quality characteristics and intramuscular connective tissue of beef semitendinosus muscle during postmortem aging for Chinese Yellow bulls. International Journal of Food Science and Technology, 43(5), 838-845. http://doi.org/10.1111/j.1365-2621.2007.01524.x

López-Maestresalas, A., Aernouts, B., Van Beers, R., Arazuri, S., Jarén, C., de Baerdemaeker, J., \& Saeys, W. (2015). Bulk Optical Properties of Potato Flesh in the 500-1900 nm Range. Food and Bioprocess Technology, 9(3), 463-470. http://doi.org/10.1007/s 11947-015-1639-0

MacDougall, D. B. (1982). Changes in the colour and opacity of meat. Food Chemistry, 9(12), 75-88. http://doi.org/10.1016/0308-8146(82)90070-X

Mager, S. R., Oomen, M. H. A., Morente, M. M., Ratcliffe, C., Knox, K., Kerr, D. J., ... Riegman, P. H. J. (2007). Standard operating procedure for the collection of fresh frozen tissue samples. European Journal of Cancer, 43(5), 828-834. http://doi.org/10.1016/j.ejca.2007.01.002

Millar, S. J., Moss, B. W., \& Stevenson, M. H. (1996). Some observations on the absorption spectra of various myoglobin derivatives found in meat. Meat Science, 42(3), 277-288. http://doi.org/10.1016/0309-1740(94)00045-X

Nicolaï, B. M., Beullens, K., Bobelyn, E., Peirs, A., Saeys, W., Theron, K. I., \& Lammertyn, J. (2007). Nondestructive measurement of fruit and vegetable quality by means of NIR spectroscopy: A review. Postharvest Biology and Technology, 46(2), 99-118. http://doi.org/10.1016/j.postharvbio.2007.06.024

Nicolaï, B. M., Defraeye, T., De Ketelaere, B., Herremans, E., Hertog, M. L. a T. M., Saeys, W., ... Verboven, P. (2014). Nondestructive measurement of fruit and vegetable quality. Annual Review of Food Science and Technology, 5, 285-312. http://doi.org/10.1146/annurev-food-030713-092410

Pastsart, U., De Boever, M., Claeys, E., \& De Smet, S. (2013). Effect of muscle and postmortem rate of $\mathrm{pH}$ and temperature fall on antioxidant enzyme activities in beef. Meat Science, 93(3), 681-686. http://doi.org/10.1016/j.meatsci.2012.11.008

Pastsart, U., De Boever, M., Lescouhier, S., Claeys, E., \& De Smet, S. (2011). Effect of Hot Boning on Colour Stability and Antioxidant Enzyme Activities in Beef Inner and Outer Biceps femoris. In 57 th International Congress of Meat Science and Technology ( $\mathrm{p}$. 243).

Peng, Y., \& Dhakal, S. (2015). Optical Methods and Techniques for Meat Quality Inspection. Transactions of the ASABE, 58(5), 1371-1386. http://doi.org/10.13031/trans.58.11004

Prahl, S. (2011). Everything I think you should know about Inverse Adding-Doubling. Oregon: Oregon Medical Laser Center, St. Vincent Hospital., 1-74.

Prahl, S. A., van Gemert, M. J. C., \& Welch, A. J. (1993). Determining the optical properties 
of turbid mediaby using the adding-doubling method. Applied Optics, 32(4), 559-568. http://doi.org/10.1364/AO.32.000559

Prieto, N., Roehe, R., Lavín, P., Batten, G., \& Andrés, S. (2009). Application of near infrared reflectance spectroscopy to predict meat and meat products quality: A review. Meat Science, 83(2), 175-86. http://doi.org/10.1016/j.meatsci.2009.04.016

Prieto, N., Ross, D. W., Navajas, E. A., Nute, G. R., Richardson, R. I., Hyslop, J. J., ... Roehe, R. (2009). On-line application of visible and near infrared reflectance spectroscopy to predict chemical-physical and sensory characteristics of beef quality. Meat Science, 83(1), 96-103. http://doi.org/10.1016/j.meatsci.2009.04.005

Ranasinghesagara, J., \& Yao, G. (2007). Imaging 2D optical diffuse reflectance in skeletal muscle. Optics Express, 15(7), 3998-4007. http://doi.org/10.1364/OE.15.003998

Rhee, M. S., Wheeler, T. L., Shackelford, S. D., \& Koohmaraie, M. (2004). Variation in palatability and biochemical traits within and among eleven beef muscles. Journal of Animal Science, 82(2), 534-550. http://doi.org//2004.822534x

Rickansrud, D. A., \& Henrickson, R. L. (1967). Total Pigments and Myoglobin Concentration In Four Bovine Muscles. Journal of Food Science, 32(1), 57-61. http://doi.org/10.1111/j.1365-2621.1967.tb01957.x

Ripoll, G., Albertí, P., Panea, B., Olleta, J. L., \& Sañudo, C. (2008). Near-infrared reflectance spectroscopy for predicting chemical, instrumental and sensory quality of beef. Meat Science, 80(3), 697-702. http://doi.org/10.1016/j.meatsci.2008.03.009

Rowe, P. I., Künnemeyer, R., McGlone, A., Talele, S., Martinsen, P., \& Seelye, R. (2014). Relationship between tissue firmness and optical properties of "Royal Gala" apples from 400 to 1050nm. Postharvest Biology and Technology, 94, 89-96.

Saeys, W., Velazco-Roa, M. a, Thennadil, S. N., Ramon, H., \& Nicolaï, B. M. (2008). Optical properties of apple skin and flesh in the wavelength range from 350 to $2200 \mathrm{~nm}$. Applied Optics, 47(7), 908-19.

Sen, A. R., \& Sharma, N. (2004). Effect of freezing and thawing on the histology and ultrastructure of buffalo muscle. Asian-Australasian Journal of Animal Sciences, 17(9), 1291-1295.

Smith, R. D., Nicholson, K. L., Nicholson, J. D. W., Harris, K. B., Miller, R. K., Griffin, D. B., \& Savell, J. W. (2008). Dry versus wet aging of beef: Retail cutting yields and consumer palatability evaluations of steaks from US Choice and US Select short loins. Meat Science, 79(4), 631-639. http://doi.org/10.1016/j.meatsci.2007.10.028

Swartling, J., Dam, J. S., \& Andersson-Engels, S. (2003). Comparison of spatially and temporally resolved diffuse-reflectance measurement systems for determination of biomedical optical properties. Applied Optics, 42(22), 4612-20. Retrieved from http://www.ncbi.nlm.nih.gov/pubmed/12916630

Swatland, H. J. (1991). Spatial and Spectrophotometric Measurements of Light Scattering in Turkey Breast Meat Using Lasers and a Xenon Arc. Canadian Institute of Food Science and Technology Journal, 24(1-2), 27-31. http://doi.org/10.1016/S0315-5463(91)700151

Swatland, H. J. (1994). Physical measurements of meat quality: optical measurements, pros and cons. Meat Science, 36(1-2), 251-9. http://doi.org/10.1016/0309-1740(94)90044-2

Swatland, H. J. (2004). Progress in understanding the paleness of meat with a low $\mathrm{pH}$. South African Journal of Animal Sciences, 34(6SUPPL.2), 1-7.

Troy, D. J., \& Kerry, J. P. (2010). Consumer perception and the role of science in the meat industry. Meat Science, 86(1), 214-226. http://doi.org/10.1016/j.meatsci.2010.05.009

Tuchin, V. (2007). Methods and algorithms for the measurements of optical parameters of tissues. In Tissue Optics (Second Edi, pp. 143-256). Bellingham, WA: SPIE Press.

Van Beers, R., Aernouts, B., León Gutiérrez, L., Erkinbaev, C., Rutten, K., Schenk, A., ... Saeys, W. (2015). Optimal Illumination-Detection Distance and Detector Size for Predicting Braeburn Apple Maturity from Vis/NIR Laser Reflectance Measurements. Food and Bioprocess Technology, 8(10), 2123-2136. http://doi.org/10.1007/s11947015-1562-4

Van Beers, R., Aernouts, B., Reis, M. M., \& Saeys, W. (2017). Anisotropic light propagation 
in bovine muscle tissue depends on the initial fiber orientation, muscle type and wavelength. Optics Express, 25(18), 22082-22095. http://doi.org/10.1364/OE.25.022082

Van Beers, R., Aernouts, B., Watté, R., Schenk, A., Nicolaï, B., \& Saeys, W. (2017). Effect of maturation on the bulk optical properties of apple skin and cortex in the 500 to $1850 \mathrm{~nm}$ wavelength range. Journal of Food Engineering, Submitted.

Van Oeckel, M. J., Warnants, N., \& Boucqué, C. V. (1999). Measurment and prediction of pork colour. Meat Science, 52, 347-354.

Von Seggern, D. D., Calkins, C. R., Johnson, D. D., Brickler, J. E., \& Gwartney, B. L. (2005). Muscle profiling: Characterizing the muscles of the beef chuck and round. Meat Science, 71(1), 39-51. http://doi.org/10.1016/j.meatsci.2005.04.010

Wang, W., \& Li, C. (2013). Measurement of the light absorption and scattering properties of onion skin and flesh at 633nm. Postharvest Biology and Technology, 86, 494-501. http://doi.org/10.1016/j.postharvbio.2013.07.032

Watté, R., Aernouts, B., Van Beers, R., Herremans, E., Ho, Q. T., Verboven, P., ... Saeys, W. (2015). Modeling the propagation of light in realistic tissue structures with MMC-fpf: a meshed Monte Carlo method with free phase function. Optics Express, 23(13), 17467. http://doi.org/10.1364/OE.23.017467

Watté, R., Aernouts, B., Van Beers, R., Postelmans, A., \& Saeys, W. (2016). Computational optimization of the configuration of a spatially resolved spectroscopy sensor for milk analysis. Analytica Chimica Acta, 917, 53-63. http://doi.org/10.1016/j.aca.2016.02.041

Xia, J. J., Berg, E. P., Lee, J. W., \& Yao, G. (2007). Characterizing beef muscles with optical scattering and absorption coefficients in VIS-NIR region. Meat Science, 75(1), 78-83.

Xia, J., Weaver, A., Gerrard, D. E., \& Yao, G. (2008). Distribution of optical scattering properties in four beef muscles. Sensing and Instrumentation for Food Quality and Safety, 2(2), 75-81.

Xia, X., Kong, B., Liu, J., Diao, X., \& Liu, Q. (2012). Influence of different thawing methods on physicochemical changes and protein oxidation of porcine longissimus muscle. LWT Food Science and Technology, 46(1), 280-286. http://doi.org/10.1016/j.lwt.2011.09.018

Yavari, N. (2006). Optical spectroscopy for tissue diagnostics and treatment control. Doctoral Thesis. Retrieved from http://bora.uib.no/handle/1956/1684

Zamora-Rojas, E., Aernouts, B., Garrido-Varo, A., Pérez-Marín, D., Guerrero-Ginel, J. E., \& Saeys, W. (2013). Double integrating sphere measurements for estimating optical properties of pig subcutaneous adipose tissue. Innovative Food Science \& Emerging Technologies, 19, 218-226.

Zamora-Rojas, E., Garrido-Varo, A., Aernouts, B., Pérez-Marín, D., Saeys, W., Yamada, Y., \& Guerrero-Ginel, J. E. (2014). Understanding near infrared radiation propagation in pig skin reflectance measurements. Innovative Food Science and Emerging Technologies, 22, 137-146. http://doi.org/10.1016/j.ifset.2014.01.006

Zijp, J. R., \& ten Bosch, J. J. (1998). Optical properties of bovine muscle tissue in vitro; a comparison of methods. Physics in Medicine and Biology, 43, 3065-3081. 